\section{Conclusions}

The interim nature of this report must be emphasized. Clearly no final comprehensive verdict can be reached at this early stage regarding the relative worth of these three operations in the elective treatment of duodenal ulcer, but the following conclusions seem justified.

1. Because of the way in which the trial is conducted, the complete absence of operative mortality almost certainly does not accurately reflect the relative hazards of the three operations if used exclusively, but it shows that, with a certain amount of selection, even resection procedures can in the hands of experienced gastrectomists be remarkably safe at the present time.

2. There is significantly less nutritional upset after vagotomy and gastro-enterostomy than after subtotal gastrectomy. In its effect on nutrition vagotomy and antrectomy apparently uccupies a position midway between these two operations.

3. With the exception of early dumping, diarrhoea, and heartburn, most of the common symptoms due to post-operative disturbance of alimentary function occurred with roughly equal frequency after the three operations. Early dumping was encountered a good deal more often after subtotal gastrectomy than after vagotomy and gastro-enterostomy or antrectomy; overall, the difference was not statistically significant, but if only the moderate and severe grades of the symptoms are considered there is a significant difference. On the other hand, diarrhoea was much more frequent after vagotomy, particularly with gastro-enterostomy, than after subtotal gastric resection, and this latter difference was significant. It is only fair to add that the number of patients inconvenienced by post-vagotomy diarrhoea, which was often episodic, very mild, and infrequent, was quite small.

4. So far the incidence of proved or strongly suspected recurrent ulceration, which has amounted to only 9 instances in the 360 traced cases in the trial and occurred after all three operations, is too small to permit of any deductions concerning the relative effectiveness of the different methods in curing the ulcer diathesis.

5. If the overall functional state and general well-being of the patients are assessed by the Visick system of grading, the results of subtotal gastrectomy seem slightly better than in those of either of the other two operations, and especially of vagotomy and gastro-enterostomy, but these differences are not statistically significant. The reason for the greater number of failures after the latter two procedures is not a higher incidence of recurrent ulceration but the more frequent development of symptoms due to alimentary dysfunction, such as bile-vomiting, postprandial epigastric fullness, flatulence, heartburn, and diarrhoea. It would be reasonable to speculate whether fewer troubles of this kind might not have been encountered if pyloroplasty had replaced gastro-enterostomy as the drainage operation, if a Billroth I reconstruction had replaced that of Polya after antrectomy, and if selective vagotomy had been used instead of total abdominal vagotomy as the method of denervation. The merits of these alternative techniques are now under investigation.

\section{Summary}

Provided no special contraindication existed, such as a very adherent posterior-wall ulcer, cases coming to elective surgery were allotted in random fashion at laparotomy to the three methods under trial. Between 1959 and 1962360 patients were thus distributed more or less evenly to the trial operations. There were no operative deaths, but 13 subsequent deaths sccurred, unrelated to operation; two patients were untraced. The results in this study were determined on the latest followup findings available on each case, which ranged from one to four years. At follow-up patients were usually interviewed "blindly" by a small panel.

Recurrence has been infrequent to date after all three operations, making worth-while comparison impossible.

The incidence of most "post-gastrectomy" syndromes was roughly the same after the three operations. But early dumping was significantly more common after subtotal gastrectomy, and diarrhoea (usually mild and episodic) after vagotomy, especially with gastro-enterostomy.

Weight loss was significantly greater after subtotal gastrectomy than after vagotomy and gastro-enterostomy ; vagotomy and antrectomy occupied an intermediate position in this respect.

Grading of the overall results on the Visick scale showed no significant difference in the outcome after the three operations.

We should like to express our thanks to the following for their assistance in the conduct of this inquiry: to our surgical colleagues for enduring with such good will the somewhat irksome discipline of a controlled trial ; to Richard Bennett, David Johnston, Andrew Jowett, and James Watts, all members of the staff of the University Department of Surgery, Leeds, for their assiduity and success in tracing a number of patients who had been temporarily lost to follow-up ; to Mr. G. S. James, of the Department of Mathematics, University of Leeds, for much helpful advice from the statistical point of view ; to Miss Elaine Smith, Mrs. R. Nicolson, and Mrs. J. King for their indefatigable secretarial services ; and the Medical Research Council, the Board of Governors of the United Leeds Hospitals, and the York Peptic Ulcer Research Trust for grants to defray some of the costs of the investigation.

\section{REFERENCE}

Dragstedt, L. R. (1962). "Section of the vagus nerves for duodenal ulcer," in Surgery of the Stomach and Duodenum, edited by H. N. Harkins and L. M. Nyhus. Churchill, London.

\title{
Bowel Habit After Vagotomy and Gastrojejunostomy
}

\author{
ALAN G. COX,* M.D. ; MICHAEL R. BOND, $\dagger$ M.B., CH.B.
}

Brit. med.7., 1964, 1, 460-465

The surgical treatment of chronic duodenal ulcer continues to pose many difficult and as yet unsolved problems. Chief among these is the choice of procedure which meets the three main requirements of low mortality rate, low recurrence rate, and freedom from troublesome sequelae such as impaired nutrition, dumping symptoms, and bilious vomiting. No gastric operation is entirely blameless in all respects, but vagotomy with a drainage procedure now finds favour with many surgeons who hold that it provides the best combination of these aims. However, vagotomy has been criticized as leading to an allegedly high incidence of diarrhoea, but, despite many references to this complication, disagreement continues regarding its cause

* Research Assistant, University Department of Surgery, Royal Infirmary, Sheffield. Present address : Department of Surgery, Western InfirmSheffield. Pres,
ary, Glasgow.

† Assistant Lecturer, University Department of Surgery, Royal Infirmary, Sheffield. 
and severity. In this paper the reasons for disagreement are clarified 'ry a review of the literature, and a detailed analysis is made of bowel habit in a series of patients after vagotomy and gastrojejunostomy.

\section{Review of Literature}

The published observations on bowel habit made by workers who have studied the results of vagotomy in some detail show a wide spectrum of opinion as reflected in the following quotations from different papers: diarrhoea is " the main drawback of any vagotomy operation" (Hendry, 1961) ; " post-vagotomy diarrhoea is a troublesome symptom" (Burge and Clark, 1960); "post-operative diarrhoea has been a minor problem" (Edwards et al., 1963) ; "vagus section has had the unexpected effect of relieving constipation" (Orr and Johnson, 1949); "constipation was also a complaint in a number of cases" (Crile et al., 1949).

There is agreement that bowel habit changes in many patients after vagotomy, and four patterns of change are described. Firstly, a minority of patients become constipated. Secondly, a few have diarrhoea lasting a few days or weeks after operation. Thirdly, an appreciable number have more frequent bowel movements daily after vagotomy. Finally, some experience episodes of diarrhoea.

In an attempt to evaluate the incidence and severity of these changes we have collected the data from papers relating to vagotomy alone and when combined with either gastrojejunostomy or pyloroplasty. In many papers the information provided is so scanty that it is valueless. Of 49 publications in which reference to post-vagotomy diarrhoea is made only six give a meaningful definition of the term diarrhoea. Few authors subdivide their cases into different types of diarrhoea, or record simple facts such as daily stool number and frequency and duration of episodes of diarrhoea. In several series of cases a variety of procedures had been performed with vagotomy but no attempt was made to report the incidence of diarrhoea after each procedure separately. This lack of precise information may in large measure explain the disagreement on the nature and severity of diarrhoea after vagotomy, and renders a detailed review of the literature more misleading than valuable.

By taking data from papers which provide a basic minimum of information, some indication can be obtained of the overall incidence of diarrhoea (Table I). When all varieties of all grades of severity are taken into account, the symptom has been observed in more than half the patients having vagotomy alone, but in only between 20 and $25 \%$ when a drainage procedure is added. Diarrhoea sufficient to be troublesome has been noted in $13 \%$ of patients treated by vagotomy alone, but in only $2 \%$ when the stomach is drained simultaneously by gastroenterostomy or pyloroplasty. It can be concluded that diarrhoea follows vagotomy alone or with a drainage procedure in an appreciable proportion of cases and is troublesome in a few. Many authors imply that the episodic type of diarrhoea causes most distress.

TABLE I.-Incidence of Diarrhoea after Vagotomy (collected data from 25 papers)

\begin{tabular}{|c|c|c|c|c|}
\hline & $\begin{array}{l}\text { Vagotomy } \\
\text { Alone }\end{array}$ & $\begin{array}{l}\text { Vagotomy }, \pm \\
\text { "Drainage" } \neq\end{array}$ & $\begin{array}{l}\text { Vagotomy }+ \\
\text { Gastro- } \\
\text { jejunostomy }\end{array}$ & $\begin{array}{c}\text { Vagotomy } \\
\text { Pyloro- } \\
\text { plasty }\end{array}$ \\
\hline $\begin{array}{l}\text { No. of papers reviewed.. } \\
\text { Total No. of patients } \\
\% \text { of patients with } \\
\text { diarrhoea: }\end{array}$ & $\begin{array}{c}9 \\
1,012\end{array}$ & $\begin{array}{r}6 \\
677\end{array}$ & $\begin{array}{c}14 \\
2,096\end{array}$ & $\begin{array}{r}2 \\
334\end{array}$ \\
\hline $\begin{array}{l}\text { All types } \\
\text { Troublesome... }\end{array}$ & $\begin{array}{l}55 \% \\
13 \%\end{array}$ & $\begin{array}{r}25 \% \\
3 \%\end{array}$ & $19 \%$ & $\begin{array}{l}25 \% \\
2 \%\end{array}$ \\
\hline
\end{tabular}

* Drainage $=$ gastrojejunostomy or pyloroplasty not specified.

\section{Follow-up Study}

Clinical Material.-A consecutive series of 120 patients who had had vagotomy and gastrojejunostomy approximately four years previously was selected for study. In all cases the operation had been performed for chronic duodenal ulcer, and there was no other significant abnormality in the alimentary tract. Of the 120 patients, 100 were available for detailed follow-up; the remaining 20 were lost to the main study for various reasons (Table II) and will be referred to separately. The 100 patients in the main study comprised 79 males and 21 females; the mean period of follow-up was 45 months after operation, with a range of 37 to 57 months.

$$
\begin{aligned}
& \text { Table 1I.-Reasons for } 20 \text { Patients Being Lost to Main Follow-up } \\
& \begin{array}{c}
\text { No. of } \\
\text { Patients }
\end{array}
\end{aligned}
$$

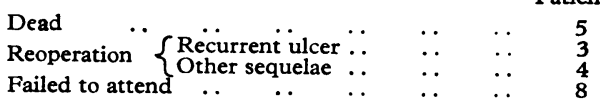

Method of Study.-Of the 100 patients followed up in detail, 95 attended for personal interview and were questioned closely regarding their progress since operation. Particular attention was given to details of bowel habit both before and after operation. The remaining five patients lived at a distance and filled in a postal questionary ; their answers appeared to be satisfactory and were included in the main study. The history and out-patient records of the 20 patients lost to the main study were reviewed and provided information which seemed to be of sufficient importance to require mention.

Operative Procedure.-Subdiaphragmatic vagotomy and posterior gastrojejunostomy was performed in all cases. No attempt was made to preserve non-gastric branches of the vagus nerves. Post-operative insulin tests were performed on a few patients, but the number is not sufficient to merit a detailed analysis of the findings based upon this criterion of the completeness of vagotomy. A recent study from this department suggests that the incidence of adequate vagal-nerve section is approximately $90 \%$ (Ross and Kay, 1964).

\section{Results in Main Study (100 Patients)}

Only 16 patients had noticed no change in their bowel habit after operation. Of the remainder, 5 had less frequent bowel movements, 10 had had transient diarrhoea, 71 had an increase in their daily bowel frequency, and 31 reported episodes of diarrhoea. The sum of these numbers is greater than 100 because several patients appear in more than one category. More detailed attention is now given to these four groups.

\section{Less Frequent Bowel Movements}

This change, reported by five patients, was slight when expressed simply as decrease in the number of bowel movements per day. However, two patients had found it necessary to start using aperients and two used more than before operation. Three of the patients were disappointed by this change.

\section{Transient Diarrhoea}

Ten patients recalled a phase of transient diarrioea after operation. The individual details of the type and duration of diarrhoea are given in Table III, which shows that the

Table III.-Type and Duration of Transient Diarrhoea in 10 Patients after Vagotomy + Gastrojejunostomy

\begin{tabular}{l|c}
\hline Daily Diarrhoea & Episodic Diarrhoea \\
\hline 2 weeks & 6 months \\
2 weeks & 1 year \\
3 weeks & 2 years \\
"A few weeks" & 3 years \\
3 months & \\
\hline
\end{tabular}


symptom settled within a few months in the majority of patients but persisted for a year in a few.

\section{More Frequent Bowel Movements}

Seventy-one patients had noticed an increase in their preoperative bowel frequency. The daily number of stools in these patients and in those with a reduced or unchanged bowel frequency is detailed in Table IV. Eighty-nine patients had two or less motions per day; of the 11 with three or more motions daily none had more than five daily bowel movements. It is clear that daily bowel frequency can be regarded as normal in the majority of patients after vagotomy and gastrojejunostomy.

\begin{tabular}{|c|c|c|c|c|c|c|}
\hline \multirow{2}{*}{\multicolumn{2}{|c|}{ Change in Prequency }} & \multirow{2}{*}{$\begin{array}{l}\text { No. of } \\
\text { Patients }\end{array}$} & \multicolumn{4}{|c|}{ Post-vagotomy Daily Stool Number } \\
\hline & & & Up to 1 & 1-2 & 2 & 3 or More \\
\hline $\begin{array}{l}\text { Increased } \\
\text { Unchanged } \\
\text { Decreased }\end{array}$ & $\because$ & $\begin{array}{r}71 \\
24 \\
5\end{array}$ & $\begin{array}{r}29 \\
13 \\
3\end{array}$ & $\begin{array}{r}20 \\
4 \\
2\end{array}$ & $\begin{array}{r}14 \\
4 \\
0\end{array}$ & $\begin{array}{l}8 \\
3 \\
0\end{array}$ \\
\hline Total & .. & 100 & 45 & 26 & 18 & 11 \\
\hline
\end{tabular}

Two other features of bowel frequency were elicited and deserve mention. An irregular bowel habit was reported by 45 patients before operation, but by only 16 after vagotomy and gastrojejunostomy. Secondly, 50 patients had taken aperients before operation, and this had been a frequent practice with many. At follow-up, only 10 patients had taken any aperients since operation ; of these, eight were merely continuing their pre-operative practice, but two had started using aperients for the first time.

Changes in the character of the stool were also recorded. Since objective measurement of these qualitative changes could not be made, reliance had to be placed upon the patients' own observations. However, there appears to be a definite tendency for the motions to become softer and paler after vagotomy and gastrojejunostomy (Table V). Very few patients had noticed any change towards darker or harder motions. Other features noted were: occasional stool frothiness ( 3 patients), a tendency to float ( 9 patients), and an unduly offensive odour (10 patients).

TABLE V.-Stool Colour and Consistency Before and After Vagotomy +

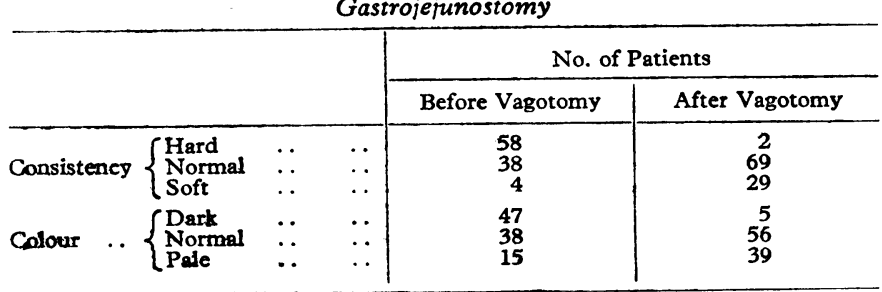

\section{Episodic Diarrhoea}

Thirty-one patients reported episodes of diarrhoea still occurring at the time of follow-up. Eight of these were unable to characterize their attacks in any detail, and generally remarked that they had some looseness of the stool after milk or beer, or that they had had identical symptoms before operation. The episodes were dismissed as trivial by the patients and will not be considered further.

The remaining 23 patients supplied more detailed information about their attacks of diarrhoea which tended to conform to a standard pattern in the individual patient. The data in this group are therefore amenable to closer scrutiny.

Fig. 1 shows the duration, frequency, and number of motions in each attack in this group of patients. Most episodes lasted for a few hours to a day. Less than half recurred at intervals of two weeks or less, and the interval between the ramainder varied from one month to a year. In the majority of patients up to five motions were passed, but three had attacks characterized by the passage of 11 to 20 motions. The motions in the attacks of diarrhoea were described by most patients as loose or watery and were occasionally associated with a sense of urgency. Three patients stated that there had been a gradual improvement in their attacks with time.

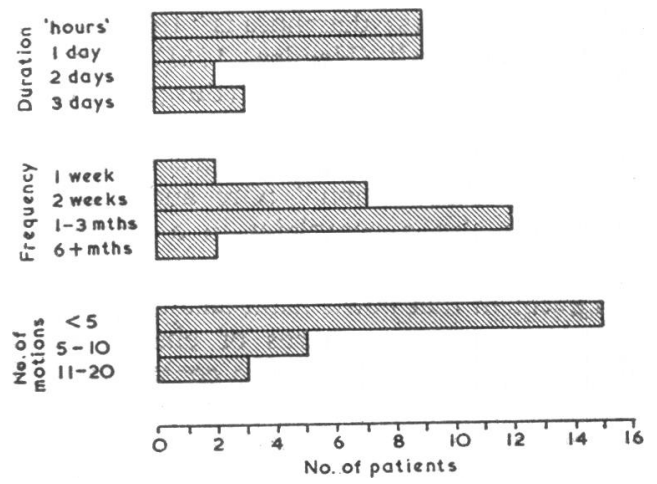

Fig. 1.-Duration, frequency, and number of motions in the episodes of diarrhoea reported by 23 patients.

The distress to the patient caused by these episodes is difficult to evaluate but depends in part upon the three factorsfrequency, duration, and number of motions in each attack. Fig. 2 illustrates the relationships between these factors, and shows that there is a tendency for the more frequent attacks to be of relatively short duration and to consist of a small

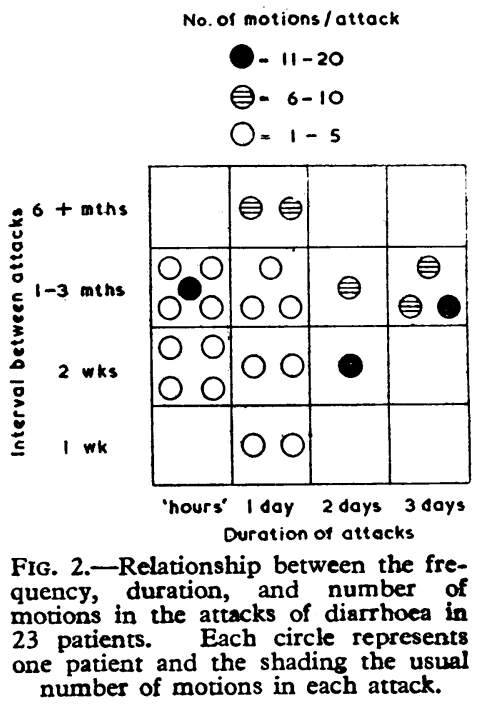

number of motions ; conversely, the less frequent attacks tend to last longer and to consist of a larger number of motions. The attacks occurring at intervals of two weeks or less are likedy to be most troublesome to the patient. Of the nine patients with attacks of this frequency, only one had episodes lasting two days, on each of which he passed six motions.

\section{Subjective Reactions to Altered Bowel Habit}

The patients were invited to comment on their bowel habit since operation. The replies (Table VI) are open to criticism on the grounds of patient and observer bias, but the patients were deliberately encouraged to be quite frank in their remarks. A high proportion regarded increased bowel frequency as a definite, if unexpected, benefit of operation. This finding 
receives some objective support from the number of patients who abandoned the use of aperients after operation.

TABLE VI.-Subjective Reactions to Daily Bowel Frequency After Vagotomy + Gastrojejunostomy

\begin{tabular}{ccc|c|c|c|c}
\hline & & & \multicolumn{3}{|c|}{$\begin{array}{c}\text { Change in Bowel Frequency } \\
\text { After Operation }\end{array}$} & Total \\
\cline { 3 - 5 } & & & Increased & Same & Decreased & \\
\hline Pleased & $\ldots$ & $\cdots$ & 55 & 6 & 1 & 62 \\
Indifferent & $\cdots$ & $\cdots$ & 11 & 18 & 1 & 30 \\
Disappointed & $\cdots$ & $\cdots$ & 5 & 0 & 3 & 8 \\
\hline Totals &. &. & 71 & 24 & 5 & 100 \\
\hline
\end{tabular}

A total of 15 patients made some complaint of alteration in bowel habit. Three were disappointed with the change to constipation and five with increased bowel frequency, in one of whom episodes of diarrhoea were also a nuisance. Six complained of episodes of diarrhoea and one of irregularity. In 10 of these 15 patients the complaint was extremely mild ; five considered the alteration in bowel habit to be a drawback of the operation.

Six patients had received treatment for diarrhoea at some stage since operation. Two of these had had transient diarrhoea, and the remainder found kaolin and morphine mixture or codeine useful in controlling undue frequency or attacks of diarrhoea.

\section{Results in 20 Patients Lost to Main Study (see Table II)}

The case records of 13 patients who had died or did not attend for review yielded some information regarding bowel habit, and Table VII shows that none had troublesome diarrhoea.

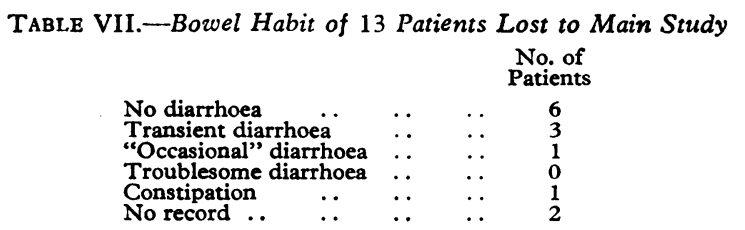

Of the seven patients subjected to further gastric surgery five are of relatively minor interest with respect to bowel habit. In three the operation was for recurrent ulceration, in one for mechanical obstruction of the efferent loop; and in one for dumping symptoms without diarrhoea. None of these are troubled by diarrhoea.

The remaining two patients are of considerable interest and merit more detailed description.

\section{Case 1}

Three weeks after an uneventful vagotomy and gastrojejunostomy a man aged 58 was readmitted because of severe diarrhoea with 14 loose stools daily. He was found to have steatorrhoea $(27.7 \mathrm{~g}$. fatty acid/day), which responded to oral neomycin and codeine with a reduction in the daily stool number to 2 or 3 . Subsequently episodes of diarrhoea and bowel frequency were kept under control with codeine phosphate. Approximately two years after operation an afferent loop approximately $18 \mathrm{in} .(45.7 \mathrm{~cm}$.) long was unexpectedly found at laparotomy performed because of recurrence of severe diarrhoea and loss of weight. The gastrojejunostomy was undone and a pyloroplasty performed. In the following two years there have been no episodes of diarrhoea and the daily stool number is 1 or 2.

Comment.-The initial response to oral neomycin suggested a "blind-loop" syndrome which was supported by the finding of a long afferent loop and the return to a normal bowel habit after restoration of gastroduodenal continuity.

\section{Case 2}

After vagotomy and gastrojejunostomy, a woman aged 48 complained of poor appetite, reduced intake of food, postprandial lethargy, bilious vomiting, and severe diarrhoea. In addition to a general increase of bowel frequency, she had episodes of diarrhoea often occurring several times a week, lasting one to two hours, during which she was scarcely able to leave the lavatory because of the almost continuous passage of loose stools. Failure to improve led to laparotomy, at which a pyloroplasty was substituted for the gastrojejunostomy. Subsequently her bowel habit was normal except for mild attacks of diarrhoea once a month. Her other symptoms had virtually disappeared.

Comment.-The substantial improvement after restoration of gastroduodenal continuity indicates that the gastrojejunostomy was an important factor in causing her diarrhoea.

\section{Discussion}

This study was made to provide information on the confused subject of bowel habit after vagotomy and gastrojejunostomy. Although our clinical material probably includes some patients with inadequate vagotomy, the findings seem to be definite enough to illustrate the main features of bowel habit after the operation. Furthermore, the method of study and analysis represents an attempt to put into perspective the problem of post-vagotomy diarrhoea.

Some workers have regarded diarrhoea as a major disadvantage of the operation and others have dismissed it as unimportant. In a review of the literature, the reasons for wide divergence of opinion became apparent. Many workers have confined themselves to broad generalizations without giving the factual data to support their conclusions. Others have published figures for the incidence of diarrhoea in a series of cases without a clear definition of the term diarrhoea.

A universally acceptable definition would be hard to make, and in these circumstances every use should be made of objective data, such as the daily number of stools and frequency of attacks of diarrhoea ; few workers have reported these simple parameters of bowel habit. For these reasons little reliable information can be extracted from the literature. However, a clear pattern emerges of four different types of alteration in bowel habit which occur after vagotomy and gastrojejunostomy. All four were found in our own study and are discussed in turn.

First, a few patients develop a tendency to constipation, usually of mild nature. It was seen in five of our patients and has been reported by others (Crile et al., 1949 ; Elliot-Smith et al., 1961 ; Holt and Lythgoe, 1961-2). Although comparatively rare, its occurrence suggests that bowel frequency can change in both directions after vagotomy and gastrojejunostomy.

Second, some patients experience diarrhoea transiently after operation. Ten of our patients recalled diarrhoea of this variety. This occasional tendency to spontaneous improvement merits comment on two grounds. It provides some justification for giving the patient with early post-operative diarrhoea some assurance that there is a chance of remission. Follow-up studies on the incidence of diarrhoea after vagotomy should take this factor into account, and one year is probably the earliest at which the permanent effects of vagotomy on bowel habit can be judged.

Third, many patients experience an increase in daily bowel frequency. Seventy-one patients said that their daily bowel frequency had increased, but in few could it be regarded as abnormally high. Of the 11 patients with three or more stools per day, none opened their bowels more than five times daily.

Fourth, a group of 23 patients reported episodes of diarrhoea after operation. The attacks, which occurred at intervals of a week to a few months, lasted a few hours to three days, during which several loose stools were passed, occasionally with a sense of urgency.

While the exact incidence of diarrhoea after vagotomy and gastrojejunostomy is difficult to assess, the distress due to altered bowel habit can be evaluated. In the papers reviewed, the incidence of troublesome diarrhoea ranged from $1 \%$ to $8 \%$. An 
intermediate figure of approximately $5 \%$ may be taken to represent the incidence of troublesome diarrhoea, but truly disabling diarrhoea is probably much rarer. In the present study a precise incidence of troublesome diarrhoea has not been given, since this would merely reflect our criteria for the condition and the patient's reaction to his symptoms. Because of this a precise value would be artificial and therefore misleading. It seems more helpful to report the objective findings and refer to the patients who complained of their bowel habit. There was no example of crippling diarrhoea, and even the two patients judged to merit revisional surgery for this and other symptoms had been able to continue their normal activities. Of the remainder who made some complaint of diarrhoea five thought that it detracted from the success of the operation in relieving pain. Our own observations indicated that it is the episodic type of diarrhoea which usually causes distress, and this has some relevance to the treatment and prophylaxis of the condition.

In trying to assess the clinical importance of diarrhoea after vagotomy and gastrojejunostomy some account should also be taken of the real pleasure with which many patients react to the change in their bowel habit; furthermore, many of the patients with episodes of diarrhoea regard this symptom as a triviality.

The present study provides further confirmation that troublesome diarrhoea, although it occurs in only a small minority of patients, constitutes a genuine problem after vagotomy and gastrojejunostomy. Its pathogenesis remains unknown, although infective enteritis and the effects of vagal denervation of the pancreas, biliary tree, and small bowel are suggested possibilities. None of these has received any degree of substantial proof and each merits consideration.

The infective hypothesis was given prominence by Dragstedt and Woodward (1951), who postulated that gastric stasis and hypochlorhydria predisposed to bacterial fermentation in the stomach, with diarrhoea following upon discharge of the infected material into the intestine. There is clinical evidence that gastric stasis plays an important part. When vagotomy was practised without gastric drainage a disturbingly high proportion of patients developed severe diarrhoea which could be relieved by either gastrojejunostomy or pyloroplasty. When the drainage procedure became a standard part of the operation of vagotomy, the incidence of diarrhoea fell to its present low levels. Infection may play a part in post-vagotomy diarrhoea in a different way, as illustrated by the patient in the present study whose diarrhoea responded to neomycin and who was found to have an unexpectedly long afferent loop at laparotomy. This type of "blind-loop" syndrome would not occur after pyloroplasty, which has been completely effective in relieving diarrhoea in this patient.

The suggestion has been made that post-vagotomy diarrhoea is a consequence of vagal denervation of the pancreas and biliary tree, or of the small intestine. For this reason " selective" vagotomy has been advocated, in which the vagal branches to the stomach are cut but the non-gastric branches are preserved; these are the coeliac branches of the posterior vagus $t$ and the hepatic branch of the anterior vagus. Although the concept of a total gastric vagotomy without denervation of extragastric structures seems sound, there are theoretical reasons to suspect that it may not solve the clinical problem of diarrhoea. First, troublesome post-vagotomy diarrhoea is generally episodic in nature and the results of nerve section are agreed to be constant and not fluctuating. Next, denervation of the pancreas is unlikely to affect its secretions, which are very largely under hormonal control (Harper, 1959). Again, stool pallor after vagotomy has been ascribed to lack of bile-pigment secretion due to denervation of the liver and biliary tree ; if this were true the patients would become jaundiced. A better explanation would be pigment dilution in more bulky stools or pigment reduction by abnormal flora (Frazer, 1955). Finally, altered intestinal motility due to autonomic imbalance may be an important factor, but experimental observations on the subject are so conflicting that no valid conclusion can be drawn (Machella and Lorber, 1948 ; Beal and Dineen, 1950 ; Faik, Grindlay, and Mann, 1950 ; Waddell and Wang, 1952-3 ; Roth and Beams, 1959).

A number of surgeons have put this hypothesis to the practical test by a study of diarrhoea in patients who have had total vagotomy and selective vagotomy (Franksson, 1948 ; Burge, 1960 ; Elliot-Smith et al., 1961 ; Kraft et al., 1962 ; Griffith, 1962). An early study by Burge and Clark (1959) suggested that preservation of the coeliac branch of the posterior vagus reduced the incidence of diarrhoea, but this was not confirmed when more cases were studied. More recently, Burge et al. (1961) have claimed a diminished incidence of diarrhoea when both the coeliac and hepatic vagal branches are preserved. The claim rests on a rather fine distinction between grades of diarrhoea, and the number of cases involved must leave some doubt whether the hypothesis can be sustained without more detailed study. A further aspect of their report, which has received little attention, is that approximately half of their cases had a tendency to more frequent bowel movements whether a standard or selective vagotomy was performed, suggesting that selective vagotomy does not eliminate alteration in bowel habit when combined with gastrojejunostomy.

Others have reported similar findings, but their conclusions are based on such slender evidence that they add no real substance to the discussion (Kraft et al., 1962; Griffith, 1962). In a careful review of their cases Elliot-Smith et al. (1961) concluded that selective vagotomy made no difference to the incidence of diarrhoea. A properly designed trial is clearly required to establish the truth or otherwise of the hypothesis; particular attention should be given to details of bowel habit, such as the daily stool number, frequency, and duration of episodes of diarrhoea.

Meanwhile, it seems likely that several factors may contribute to the development of diarrhoea after vagotomy and gastrojejunostomy. These include gastric stasis due to an inadequate drainage procedure, the presence of a gastrojejunostomy, an unintentionally long afferent loop of jejunum, and possible vagal denervation of extragastric organs. The two cases described in this paper provide some evidence that a gastrojejunostomy is itself an important factor in some cases, and lend support to the preference now given to pyloroplasty. It would be of some interest and value to have corresponding data in a series of cases after vagotomy with pyloroplasty.

\section{Summary}

A review of the literature revealed an appreciable incidence of diarrhoea after vagotomy but yielded inadequate data for proper evaluation of the clinical problem.

In a study of bowel habit in 100 patients approximately four years after vagotomy and gastrojejunostomy, four varieties of altered bowel habit emerged. Daily bowel frequency increased in 71 , episodic diarrhoea developed in 23 , transient diarrhoea had occurred in 10, and a tendency to constipation in 5 .

Although many patients were either pleased or unconcerned with the change, a few were disappointed. It is suggested that the true incidence of troublesome diarrhoea approximates to $5 \%$, but that disabling diarrhoea is much rarer.

The explanation for these changes is uncertain, but there is evidence that the type of gastric drainage procedure is a factor requiring evaluation in addition to the effects of vagal denervation of extragastric organs.

We wish to thank Professor A. W. Kay and Mr. W. J. Lytle for encouraging us to study their patients. 
REFERENCES

* Austen, W. G., and Edwards, H. C. (1961). Gut, 2, 158

Beal, J. M., and Dineen, P. (1950). Arch. Surg., 60, 203.

* Beattie, A. D. (1950). Lancet, 1, 525.

Burge, H. W. (1960). Postgrad. med. F., 36, 2.

Burge, H. W. (1960). Postgrad. med. F., 36, 2.

- and Clark, P. A. (1959). Brit. med. F., 1,

$\star$ - Rizk, A. R., Tompkin, A. M. B., Barth, C. E., Hutchison, J. S. F., Longland, C. J., McLennan, I., and Miln, D. C. (1961). Lanost, 2, 897.

* Clark, C. G. (1961). Brit. med. f., 1, 1250

* Crile, G., Jones, T. E., and Davis, J. B. (1949). Ann. Surg., 130, 31.

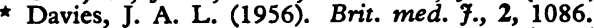

Dragstedt, L. R., and Woodward, E. R. (1951). F. Amer. med. Ass., 145,795 .

^ Edwards, L. W., and Herrington, J. L. (1953). Ann. Surg., 137, 873.

Elliot-Smith, A., Painter, N. S., and Porter, R. (1961). Lancet, 2, 1036.

Faik, S., Grindlay, J. H., and Mann, F. C. (1950). Surgery, 28, 546.

* Feggetter, G. Y., and Pringle, R. (1963). Surg. Gynec. Obstet., 116, 175 .

Franksson, C. (1948). Acta chir. scand., 96, 409.

Frazer, A. C. (1955). Brit. med. f., 2, 805.

Griffith, C. A. (1962). West. ₹. Surg., 70, 175

* Grimson, K. S., Rowe, C. R., and Taylor, H. M. (1952). Ann. Surg, 135, 621 . $\star$ Hamilton, J. E., Harbrecht, P. J., Robbins, R. E., and Kinnaird, D. W. (1961). Ibid., 153, 934.

Harper, A. A. (1959). Gastroenterology, 36, 386.

^ Hendry, W. G. (1961). Postgrad. med. F., 37, 137.

$\star$ Henson, G. F., and Rob, C. G. (1955). Brit. med. f., 2, 588.

* Hindmarsh, F. D. (1957). Lancet, 1, 1113.

* Hoerr, S. O. (1955). Surgery, 38, 149.

* Holt, R. L., and Lythgoe, J. P. (1961-2). Brit. F. Surg., 49, 255.

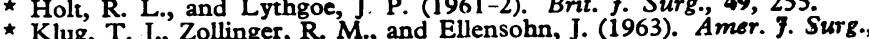

Klug, T. J., Zo.

* Kraft, R. O., Fry, W. J., and Ransom, H. K. (1962). Arch. Surg., 85, 687.

Machella, T. E., and Lorber, S. H. (1948). Gastroenterology, 11, 426.

* MacKelvie, A. A. (1957). Brit. med. f., 1, 321.

$\star$ Orr, I. M. and Johnson, H. D. (1949). Ibid., 2, 1316.

* Pollock, A. V. (1952). Lancet, 2, 795.

Ross, B., and Kay, A. W. (1964). Gastroenterology. In press.

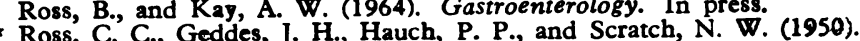
Canad. med. Ass. F., 63, 347.

Roth, H. P., and Beams, A. J. (1959). Gastroenterology, 36, 452.

$\star$ Smith, R. C., Ruffin, J. M., and Baylin, G. J. (1947). Sith. mod. $Y$. (Bgham, Ala.), 40, 1.

Waddell, W. R. and Wang C. C. (1952-3). 7. appl. Physiol., 5, 705.

W Walters, W. and Mobley, J. E. (1957). Ann. Surg., 145, 753.

* Weinstein, V. A. Hollander, F., Lauber, F. U., and Colp, R. (1950). Gastroenterology, 14, 214.

* These papers provided data for Table I.

\title{
Aspects of Nutrition after Vagotomy and Gastrojejunostomy
}

\author{
ALAN G. COX,* M.D. ; MICHAEL R. BOND, $†$ M.B., CH.B. ;DENNIS A. PODMORE, $\ddagger$ A.R.I.C. \\ DAVID P. ROSE,§ M.B., CH.B.
}

Brit. med. F., 1964, 1, 465-469

The choice of operation in the surgical treatment of chronic duodenal ulcer remains a controversial subject. Partial gastrectomy is now performed less frequently, as surgeons are increasingly attracted to the advantages of vagotomy, which effects a substantial reduction of gastric-acid secretion in most cases. Recurrent ulceration appears to be more common after vagotomy than after partial gastrectomy, but this disadvantage of vagotomy is balanced and possibly outweighed by the higher post-operative mortality rate after partial gastrectomy. The major criticism of partial gastrectomy is that it leads to an unacceptably high incidence of late complications, which include alimentary symptoms such as postprandial abdominal discomfort, dumping, and vomiting, and also impaired nutrition manifested by loss of weight, anaemia, and more rarely osteomalacia. Although agreement is not complete, many publications support the contention that untoward alimentary symptoms are comparatively infrequent after vagotomy. However, there is remarkably little information in the literature to substantiate the view that impaired nutrition is rare after vagotomy. In order to provide data relevant to this latter problem, this paper reports the results of a study of patients after vagotomy and gastrojejunostomy for chronic duodenal ulcer.

Vagotomy has been extensively used in Sheffield since 1958, and the interval between operation and the present review varied between 37 and 57 months in the patients studied; we have therefore considered the results as representing a post-operative

* Research Assistant in Surgery, University Department of Surgery, Royal Infirmary, Sheffield. Present address: Department of Surgery, Western Infirmary, Glasgow.

† Assistan Lecturer in Surgery, University Department of Surgery, Royal Infirmary, Sheffield.

‡ Principal Biochemist, Department of Chemical Pathology, United Sheffield Hospitals.

$\checkmark$ Registrar in Clinical Pathology, Department of Chemical Pathology, United Sheffield Hospitals. investigation at approximately four years. A gastric drainage procedure must be performed simultaneously with vagotomy, which by itself causes a high proportion of symptoms due to delayed gastric emptying. Gastrojejunostomy was combined with vagotomy in the present series, and the patients having pyloroplasty in the period under consideration have not been included as they were too few to merit detailed investigation. The study was designed to give as much information as possible without requiring more co-operation than could reasonably be expected from our patients. The tests were therefore restrictec to peripheral blood examination, estimation of serum-iron and serum-vitamin- $B_{12}$ levels, and measurement of vitamin- $B_{13}$ absorption and faecal fat excretion. In addition, the patients were asked about alimentary symptoms and weight changes before and after operation. Insulin tests to confirm completeness of vagotomy were not performed in all patients, but a recent study from this department suggests that vagal-nerve section was achieved in approximately $90 \%$ of patients (Ross and Kay, 1964).

\section{Clinical Material}

From a consecutive series of 120 patients with chronic duodenal ulcer treated by vagotomy and posterior gastrojejunostomy approximately four years previously, 25 were excluded because of death (5), reoperation (7), failure to attend (7), and distance from Sheffield (6). The 95 patients remaining for detailed investigation were 75 males and 20 females. Some were unable to undergo all the tests planned. All results described as "after operation" refer to the study of these patients approximately four years after vagotomy and gastrojejunostomy.

In order to have data with which to compare the results, information was taken from various sources, which are described in the next section. This information is called "control" data. 